\title{
Adição de gesso agrícola e cinza de madeira ao substrato no desenvolvimento de mudas de baruzeiro (Dipteryx alata Vog)
}

\section{Addition of agricultural plaster and wood ash to substrate in baruzeiro (Dipteryx alata Vog) seedlings developing}

\author{
Carlos Alessandro de Freitas ${ }^{1}$, Cícero José da Silva $*^{2}$, César Antônio da Silva ${ }^{3}$, Janaina Alves de Almeida ${ }^{4}$, Natália Santan \\ Rincon ${ }^{5}$
}

\begin{abstract}
Resumo: O objetivo do trabalho foi avaliar o desenvolvimento de mudas de baruzeiro (Dipteryx alata Vog) em função de proporções de gesso $(0 \% ; 1,6 \% ; 3,2 \% ; 4,8 \%$ e $6,4 \%)$ com base em volume e adubação com cinza de madeira (ausência e presença) misturadas ao substrato Bioplant ${ }^{\circledR}$. Constituiu-se assim um esquema fatorial $5 \times 2$, em delineamento inteiramente ao acaso, com três repetições e quatro plantas por parcela. O experimento foi conduzido de janeiro a março de 2009 , em viveiro com cobertura e laterais de sombrite preto ( $50 \%$ da luminosidade natural), situado na Fazenda Japão, município de Orizona, Goiás. Como recipiente foram utilizados sacos de polietileno de 15 x $25 \mathrm{~cm}$, onde colocou-se uma sementes por recipiente, ficando a extremidade superior da semente cerca de $2,0 \mathrm{~cm}$ de profundidade. As irrigações foram realizadas diariamente, no período da tarde. Aos 152 dias após a semeadura, avaliou-se altura de muda (AM), diâmetro de caule (DC), número de folha (NF), número de folíolos por folha (NFF), número de folíolos por planta (NFP), comprimento da raiz principal (CR), massa da matéria seca das raízes (MSR), massa seca da parte aérea (MSPA), massa seca total (MSTO) e índice de qualidade de Dickson (IQD). O gesso agrícola proporcionou melhor desenvolvimento inicial das mudas de baruzeiro, no entanto sua associação com cinzas de madeira, juntamente com o substrato, não favoreceu o desenvolvimento das mudas
\end{abstract}

Palavras-chaves: Produção de mudas. Adubação alternativa. Resíduos de indústria

\begin{abstract}
This study aimed to evaluate the baruzeiro seedlings development in function of plaster proportions $(0 \%$, $1.6 \%$, $3.2 \%, 4.8 \%$ and $6.4 \%$ ) based on volume and fertilization with wood ash (absence and presence) added to the substrate Bioplant ${ }^{\circledR}$. It constitutes therefore a $5 \times 2$ factorial arrangement, in a completely randomized design with three replications and four plants per plot. The experiment was conducted from January to March 2009, in coverage nursery and side with shade screen (50\% of natural light), located in Fazenda Japão, Orizona county, Goiás. As container was used polythene bags of $15 \mathrm{x}$ $25 \mathrm{~cm}$, which was placed one seeds per container, with the upper end of the seed approximately $2.0 \mathrm{~cm}$ depth. The irrigation was performed daily in the afternoon. At 152 days after sowing, was evaluated seedling height (SH), stem diameter (SD), sheet number (SN), number of leaflets per leaf (NLL), number of leaves per plant (NLP), length the main root (LR), dry mass of roots (DMR), dry mass of aerea part (DMAP), total dry matter (TDM) and Dickson quality index (DQI). The plaster provided better initial development of seedlings baruzeiro, however its association with wood ashes, along with the substrate, didn't favor the growth of seedlings.
\end{abstract}

Key words: Seedling production Alternative manure. Waste industry

\footnotetext{
*Autor para correspondência

Recebido para publicação em 03/09/2014 aprovado em 15/05/2015

${ }^{1}$ Graduando em Agronomia, Instituto Federal Goiano - Câmpus Urutaí, Urutaí - Go; Fone: (64) 9309-9442, E-mail: carloscaf77@ gmail.com

${ }^{2}$ Mestre em Fitotenia, Professor, Instituto Federal Goiano - Câmpus Morrinhos, E-mail: cicerojsil@ gmail.com

${ }^{3}$ Doutor em Ciências (Engenharia Agrícola), Professor, Instituto Federal Goiano - Câmpus Morrinhos, E-mail: cesar.ufu@gmail.com

${ }^{4}$ Graduanda em Agronomia, Instituto Federal Goiano - Câmpus Urutaí, E-mail: jana_ba_tera@ @otmail.com

${ }^{5}$ Graduanda em Agronomia, Instituto Federal Goiano - Câmpus Urutaí, E-mail: nataliagronomia.11@hotmail.com
} 


\section{INTRODUÇÃO}

O baru (Dipteryx alata Vog) é uma leguminosa arbórea frutífera da família Fabaceae, que ocorre nas matas, cerrados e cerradões do Brasil Central. É uma planta ameaçada de extinção devido ao corte indiscriminado. Sua madeira é utilizada na construção civil, indústria de móveis. Outras formas de exploração do baruzeiro, de maneira sustentável, são na produção de óleos, farelo, torta e manteiga, além de poder ser usada na alimentação (CARAZZA \& ÁVILA, 2010).

Um dos fatores prioritários para a implantação de povoamentos florestais é a qualidade da muda. Por isso, muitos esforços têm sido realizados para reduzir os custos de produção das mudas e melhorar a qualidade das mesmas (TRAZZI et al., 2013; ANDRADE et al., 2013). A utilização de materiais renováveis como fonte de nutrientes, além de ser uma interessante solução para destinação dos resíduos, pode também ser uma saída efetiva para a redução dos altos custos de insumos necessários para produção de mudas florestais (TRAZZI et al., 2013), tendo em vista sua disponibilidade e facilidade de aquisição (CALDEIRA et al., 2012).

De acordo com Correa et al. (2013) a adição de cinzas ao substrato permite melhor formação de agregados com grande quantidade de macro e micro porosidade, tornando o substrato leve, com alta qualidade para produção de mudas. Além disso, a cinza de madeira serve como adubo orgânico, sendo fonte, principalmente, de Fósforo, Potássio, Cálcio, Enxofre, Magnésio e Nitrogênio (SANTOS et al., 2013).

Broetto et al. (2009) avaliaram diversos substratos na produção mudas de maracujazeiro-azedo, constataram que quando adicionaram cinzas de madeira ao substrato, obtiveram as melhores médias de desenvolvimento vegetativo das mudas. Resultados satisfatórios utilizando cinza no substrato para produção de mudas, também foram encontrados por Silva et al. (2009), Oliveira et al. (2011) e Garlet et al. (2013) avaliando alface, barriguda e goiaba, respectivamente.

Além de resolver o problema da deficiência de cálcio, o gesso agrícola reduz a saturação de alumínio, fornece enxofre ao solo e é eficiente como melhorador do ambiente radicular nas camadas subsuperficiais (SOUZA \& LOBATO, 2004; VENTURIN et al., 1995; FREIRE et al., 2010).

Ramos et al. (2010) e Silva et al. (2013), constataram que a adição de gesso como complemento nutricional ao substrato influencia positivamente o desenvolvimento de mudas de café e maracujazeiro amarelo, respectivamente.

A associação entre gesso agrícola e cinzas de madeira é pouco estudada. Silva et al. (2013), perceberam efeito negativo para o desenvolvimento de mudas de maracujazeiro amarelo em função de proporções de gesso e adubação com cinzas de madeira.

Dessa forma, o objetivo deste trabalho foi avaliar o desenvolvimento de mudas de baruzeiro (Dipteryx alata Vog) em função de proporções de gesso agrícola e adubação com cinzas de madeira (ausência/presença).

\section{MATERIAL E MÉTODOS}

O experimento foi conduzido no período de agosto 2009 a janeiro de 2010, em viveiro com cobertura e laterais de sombrite preto (50\% da luminosidade natural), situado no município de Orizona (GO), a $17^{\circ} 02^{\prime} 17^{\prime}$ ' de latitude Sul, $48^{\circ} 17^{\prime} 48^{\prime \prime}$ de longitude Oeste e altitude de aproximadamente $830 \mathrm{~m}$.

Utilizou-se o delineamento inteiramente ao acaso, em esquema fatorial $5 \times 2$, com três repetições e quatro plantas por parcela. O primeiro fator foi constituído de cinco doses de gesso $(0 \% ; 1,6 \% ; 3,2 \% ; 4,8 \%$ e $6,4 \%)$, com base em volume, misturadas ao substrato Bioplant. $O$ segundo fator foi composto pela ausência ( $0 \%)$ e presença de cinzas de madeira $(10 \%)$

Em cada recipiente, foi acrescido junto ao substrato comercial Bioplant ${ }^{\circledR}$ uma mistura de $150 \mathrm{~mL}$ composta por uma mistura de esterco bovino curtido (20\%) + solo (20\%) para enriquecimento nutricional do substrato, além dos respectivos tratamentos, conforme descritos anteriormente.

As sementes foram coletadas de cinco árvores, em bom estado fitossanitário, no mesmo município, e semeadas uma semana após a coleta. A semeadura foi realizada em 13 de agosto de 2009, colocando-se uma semente em recipientes (saquinhos) de $15 \times 25 \mathrm{~cm}$ ficando a extremidade superior da semente cerca de $2,0 \mathrm{~cm}$ de profundidade. As irrigações foram realizadas diariamente, no período da tarde.

Aos 152 dias após a semeadura, avaliou-se altura de muda (AM), diâmetro de caule (DC), número de folha (NF), número de folíolos por folha (NFF), número de folíolos por planta (NFP), comprimento da raiz principal (CR), massa da matéria seca das raízes (MSR), massa seca da parte aérea (MSPA), massa seca total (MSTO) e índice de qualidade de Dickson (IQD).

A altura de muda e comprimento da raiz principal foram determinados com fita métrica, enquanto o diâmetro de caule foi mensurado com paquímetro manual. As raízes foram lavadas em água corrente, acondicionadas em embalagens de papel e secas em estufa de circulação e renovação de ar, a $60^{\circ} \mathrm{C}$. A parte aérea passou pelo mesmo processo de acondicionamento e secagem. O IQD foi determinado segundo metodologia proposta por Dickson (1960), em que $\mathrm{IQD}=\mathrm{MSTO} /(\mathrm{AM} / \mathrm{DC}+\mathrm{MSPA} / \mathrm{MSR})$.

Os dados coletados foram submetidos à análise de variância (teste $\mathrm{F}$ ), em níveis de $1 \%$ e $5 \%$ de probabilidade, através do software SISVAR (FERREIRA, 2011). Nas características em que houve efeito dos tratamentos, aplicouse o teste de Tukey para os fatores ausência e presença de cinza, e a análise de regressão polinomial para o fator proporções de gesso adicionadas ao substrato Bioplant ${ }^{\circledR}$.

\section{RESULTADOS E DISCUSSÃO}

A presença ou ausência de cinza influenciaram significativamente a $1 \%$ de probabilidade todas as características avaliadas em mudas de baruzeiro aos 152 dias após a semeadura, exceto para NFF que obteve significância a $5 \%$. Enquanto as proporções de gesso proporcionaram efeito sobre o CR, MSR, MSTO e IQD a $1 \%$ de probabilidade e NFF a $5 \%$ de probabilidade, enquanto as demais características não houve significância. A respeito da interação de cinza $\mathrm{x}$ gesso ocorreu efeito significativo a $1 \%$ de probabilidade para CR, MSR, MSPA, MSTO e IQD e a $5 \%$ para $\mathrm{DC}$, já os demais parâmetros não apresentaram significância (Tabela 1). 
Tabela 1. Resumo de análises de variância de altura de mudas (AM), diâmetro de caule (DC), número de folhas (NF), número de folíolos por folhas (NFF), número de folíolos por planta (NFP), comprimento de raiz principal (CR), massa de matéria seca das raízes (MSR), massa seca da parte aérea (MSPA), massa seca total (MST) e índice de qualidade de Dickson (IQD) em mudas de baruzeiros, aos 152 dias após a semeadura, em função da ausência e presença de cinza de madeira e proporções de gesso adicionadas ao substrato. Orizona (GO), 2010

\begin{tabular}{|c|c|c|c|c|c|c|c|c|c|c|c|}
\hline \multirow{2}{*}{$\begin{array}{l}\text { Causas de } \\
\text { Variação }\end{array}$} & \multirow[b]{2}{*}{ gl } & \multicolumn{10}{|c|}{ Quadrados Médios } \\
\hline & & $\begin{array}{l}\mathbf{A M} \\
(\mathbf{c m})\end{array}$ & $\begin{array}{c}\text { DC } \\
(\mathrm{mm})\end{array}$ & NF & NFF & NFP & $\begin{array}{c}\mathrm{CR} \\
(\mathrm{mm})\end{array}$ & $\begin{array}{c}\text { MSR } \\
\left(\text { g planta }^{-1}\right)\end{array}$ & $\begin{array}{c}\text { MSPA } \\
\left(\text { g planta }^{-1}\right)\end{array}$ & $\begin{array}{c}\text { MSTO } \\
\left(\text { g planta }^{-1}\right)\end{array}$ & IQD \\
\hline Cinza $(C)$ & 1 & $67,80^{* *}$ & $3,80^{* *}$ & $4,03^{* *}$ & $0,98^{*}$ & $396,03^{* *}$ & $141,56^{* *}$ & $14,80^{* *}$ & $6,63^{* * *}$ & $41,26^{* *}$ & $2,94^{*}$ \\
\hline Gesso (G) & 4 & $1,00^{\mathrm{ns}}$ & $0,26^{\mathrm{ns}}$ & $0,30^{\mathrm{ns}}$ & $0,53^{*}$ & $34,69^{\mathrm{ns}}$ & $155,90^{* *}$ & $0,56^{* *}$ & $0,10^{\mathrm{ns}}$ & $0,67^{* *}$ & $0,14^{* *}$ \\
\hline $\mathbf{C} * \mathbf{G}$ & 4 & $2,07^{\mathrm{ns}}$ & $0,38^{*}$ & $0,06^{\mathrm{ns}}$ & $0,09^{\mathrm{ns}}$ & $3,03^{\mathrm{ns}}$ & $117,76^{* *}$ & $0,21^{* *}$ & $0,50^{* *}$ & $1,15^{* *}$ & $0,13^{* *}$ \\
\hline Resíduo & 20 & 2,02 & 0,12 & 0,29 & 0,17 & 22,04 & 82,82 & 0,04 & 0,07 & 0,12 & 0,02 \\
\hline CV (\%) & & 11,33 & 6,92 & 10,45 & 5,70 & 12,28 & 7,21 & 7,24 & 15,72 & 7,46 & 8,76 \\
\hline
\end{tabular}

GL - Graus de liberdade; ${ }^{\text {ns }}$ - Não significativo pelo teste de F; ** - Significativo ao nível de $1 \%$ de probabilidade, pelo teste de F; * - Significativo ao nível de $5 \%$ de probabilidade, pelo teste de F; CV (\%) - Coeficiente de variação.

Pelo teste de Tukey, a presença de cinzas de madeira adicionada ao substrato prejudicou o desenvolvimento das mudas de baruzeiro em todos os parâmetros analisados. Apenas para as características de CR e MSPA, nas proporções de gesso de $0 \%, 1,6 \%$ e $3,2 \%$ e $0 \%$ e $1,6 \%$, respectivamente, não houve diferenças significativas (Tabela 2).

Estes resultados corroboram com os de Ferreira et al. (2009), que verificaram que a aplicação de cinzas prejudica o desenvolvimento de mudas de araticum, porém sem a associação com gesso agrícola. Resultados semelhantes, também, foram encontrados por Silva et al. (2013), que avaliaram o desenvolvimento de mudas de maracujazeiro sob adição de gesso agrícola e cinza de madeira ao substrato, segundo estes a utilização do gesso nas suas maiores proporções, combinado com a cinza, aumenta significativamente a quantidade de $\mathrm{Ca}^{2+}$ no substrato, o que pode inibir a absorção de $\mathrm{K}^{+}$e $\mathrm{Fe}^{2+}$, prejudicando, assim, o desenvolvimento das mudas.
Resultados contrários foram encontrados por Oliveira et al. (2011) onde cinza de madeira não influenciou o desenvolvimento de mudas de barriguda e por Andrade et al. (2013), onde a presença de cinzas na mistura do substrato não apresentou significância ao desenvolvimento de mudas de aroeira (exceto com relação ao comprimento das plântulas, onde sua presença trouxe efeitos negativos). Embora estes tenham trabalhado com substratos alternativos e sem associação com gesso agrícola.

Entretanto, Broetto et al. (2009) obtiveram que adição de cinzas e esterco bovino ao substrato influenciou positivamente o desenvolvimento de mudas de maracujazeiroazedo. Prado et al. (2003), Santos et al. (2013) e Silva et al. (2009), também, alcançaram resultados significativo na adição de cinzas, sem associação com gesso agrícola, para produção de mudas de goiaba, tomate e alface, respectivamente.

Tabela 2. Valores Médios de altura de muda (AM), diâmetro de caule (DC), número de folhas (NF), número de folíolos na folha (NFF), número de folíolos por planta (NFP), comprimento de raiz (CR), massa seca de raiz (MSR), massa seca da parte aérea (MSPA), massa seca total (MSTO) e índice de qualidade de Dickson (IQD) de mudas de baruzeiro, aos 152 dias após a semeadura, em função da ausência e presença de cinza de madeira e proporções de gesso adicionadas ao substrato. Orizona (GO), 2010

\begin{tabular}{|c|c|c|c|c|c|c|c|}
\hline \multirow{2}{*}{ Característica avaliada } & \multirow{2}{*}{ Cinza de madeira } & \multicolumn{5}{|c|}{ Doses de gesso $(\%)$} & \multirow{2}{*}{ Média } \\
\hline & & 0 & 1,6 & 3,2 & 4,8 & 6,4 & \\
\hline \multirow{2}{*}{$\mathrm{AM}(\mathrm{cm})$} & Ausência & 12,93 & 13,46 & 14,76 & 14,83 & 14,49 & $14,05 \mathrm{a}$ \\
\hline & Presença & 11,34 & 11,78 & 10,40 & 11,58 & 10,44 & $11,04 \mathrm{~b}$ \\
\hline DMS: $1,08 \mathrm{CV}: 11,33 \%$ & Média: & 12,14 & 12,32 & 12,58 & 13,21 & 12,47 & 12,54 \\
\hline \multirow{2}{*}{$\mathrm{DC}(\mathrm{mm})$} & Ausência & $4,90 \mathrm{a}$ & $5,39 \mathrm{a}$ & $5,58 \mathrm{a}$ & $5,81 \mathrm{a}$ & $5,87 \mathrm{a}$ & 5,51 \\
\hline & Presença & $4,77 \mathrm{~b}$ & $4,91 \mathrm{~b}$ & $4,91 \mathrm{~b}$ & $5,02 \mathrm{~b}$ & $4,38 b$ & 4,80 \\
\hline DMS: $0,61 \mathrm{CV}: 6,92 \%$ & Média: & 4,84 & 5,15 & 5,24 & 5,41 & 5,12 & 5,15 \\
\hline \multirow{2}{*}{ NF } & Ausência & 5,61 & 5,33 & 5,67 & 5,67 & 5,44 & $5,51 \mathrm{a}$ \\
\hline & Presença & 5,00 & 5,17 & 4,83 & 4,72 & 5,00 & $4,78 b$ \\
\hline DMS: $0,41 \mathrm{CV}: 10,45 \%$ & Média: & 5,31 & 4,75 & 5,25 & 5,19 & 5,22 & 5,14 \\
\hline
\end{tabular}


...Continuação da tabela 2.

\begin{tabular}{|c|c|c|c|c|c|c|c|}
\hline \multirow{2}{*}{ NFF } & Ausência & 7,11 & 7,50 & 7,83 & 7,50 & 8,00 & $7,59 a$ \\
\hline & Presença & 6,83 & 7,00 & 7,33 & 7,53 & 7,44 & $7,23 b$ \\
\hline DMS: $0,322 \mathrm{CV}: 5,70 \%$ & Média: & 6,97 & 7,25 & 7,58 & 7,51 & 7,72 & 7,41 \\
\hline \multirow{2}{*}{ NFP } & Ausência & 39,94 & 38,83 & 44,50 & 42,50 & 43,56 & $41,87 \mathrm{a}$ \\
\hline & Presença & 34,25 & 30,33 & 35,50 & 35,69 & 37,22 & $34,60 \mathrm{~b}$ \\
\hline DMS: $3,58 \mathrm{CV}: 12,28 \%$ & Média: & 37,10 & 34,58 & 40,00 & 39,10 & 40,39 & 38,23 \\
\hline \multirow{2}{*}{$\mathrm{CR}(\mathrm{cm})$} & Ausência & $26,72 \mathrm{a}$ & $28,50 \mathrm{a}$ & $33,94 \mathrm{a}$ & $31,35 \mathrm{a}$ & $31,39 \mathrm{a}$ & 30,38 \\
\hline & Presença & $26,00 \mathrm{a}$ & $28,00 \mathrm{a}$ & $30,67 \mathrm{a}$ & $25,28 \mathrm{~b}$ & $20,22 b$ & 26,03 \\
\hline DMS: $3,46 \mathrm{CV}: 7,21 \%$ & Média: & 26,36 & 28,25 & 32,31 & 28,31 & 25,81 & 28,21 \\
\hline \multirow{2}{*}{ MSR (g planta ${ }^{-1}$ ) } & Ausência & $3,27 \mathrm{a}$ & $3,36 \mathrm{a}$ & $3,82 \mathrm{a}$ & $3,93 \mathrm{a}$ & $3,59 \mathrm{a}$ & 3,59 \\
\hline & Presença & $1,72 \mathrm{~b}$ & $2,49 \mathrm{~b}$ & $2,64 \mathrm{~b}$ & $2,32 \mathrm{~b}$ & $1,76 \mathrm{~b}$ & 2,19 \\
\hline DMS: $0,36 \mathrm{CV}: 7,24 \%$ & Média: & 2,50 & 2,92 & 3,23 & 3,12 & 2,68 & 2,89 \\
\hline \multirow{2}{*}{ MSPA (g planta ${ }^{-1}$ ) } & Ausência & $1,86 \mathrm{a}$ & $1,75 \mathrm{a}$ & $2,13 \mathrm{a}$ & $2,64 \mathrm{a}$ & $2,59 \mathrm{a}$ & 2,20 \\
\hline & Presença & $1,53 \mathrm{a}$ & $1,36 \mathrm{a}$ & $1,21 \mathrm{~b}$ & $1,12 \mathrm{~b}$ & $1,07 \mathrm{~b}$ & 1,26 \\
\hline DMS: $0,46 \mathrm{CV}: 15,72 \%$ & Média: & 1,70 & 1,56 & 1,67 & 1,88 & 1,83 & 1,73 \\
\hline \multirow{2}{*}{$\operatorname{MSTO}\left(\right.$ g planta $\left.^{-1}\right)$} & Ausência & $5,3 \mathrm{a}$ & $5,12 \mathrm{a}$ & $5,96 \mathrm{a}$ & $6,57 \mathrm{a}$ & $6,18 \mathrm{a}$ & 5,79 \\
\hline & Presença & $3,25 b$ & $3,84 \mathrm{~b}$ & $3,89 \mathrm{~b}$ & $3,44 \mathrm{~b}$ & $2,83 \mathrm{~b}$ & 3,44 \\
\hline DMS: $0,59 \mathrm{CV}: 7,46 \%$ & Média: & 4,19 & 4,48 & 4,90 & 5,01 & 4,50 & 4,62 \\
\hline \multirow{2}{*}{ IQD } & Ausência & $1,60 \mathrm{a}$ & $1,69 \mathrm{a}$ & $1,86 \mathrm{a}$ & $2,07 \mathrm{a}$ & $1,95 \mathrm{a}$ & 1,83 \\
\hline & Presença & $1,00 \mathrm{~b}$ & $1,37 \mathrm{~b}$ & $1,51 \mathrm{~b}$ & $1,21 \mathrm{~b}$ & $0,95 b$ & 1,21 \\
\hline DMS: $0,23 \mathrm{CV}: 8,76 \%$ & Média: & 1,30 & 1,53 & 1,68 & 1,64 & 1,45 & 1,52 \\
\hline
\end{tabular}

Médias seguidas de mesma letra maiúscula na coluna, e minúscula na linha, não diferem entre si, pelo teste de Tukey, a 0,05 de significância. CV - Coeficiente de Variação; DMS - Diferença Mínima Significativa.

A equação de regressão quadrática foi a que melhor ajustou-se para as dosagens de gesso adicionadas ao substrato na presença de cinza quando analisou o DC, sendo que a dose de 2,67\% de gesso proporcionou o maior diâmetro de caule, com 5,0 mm. Enquanto na ausência de cinzas, ocorreu efeito linear crescente (Figura 1A). Efeito este, também verificado para o parâmetro NFF (Figura 1B). Consequência, provavelmente, da associação dos nutrientes fornecidos pela cinza, principalmente Nitrogênio e Cálcio, com os oriundos do gesso, sobretudo Enxofre e Cálcio, que são essenciais para uma utilização eficiente de nitrogênio, o que favoreceu o desenvolvimento foliar, fato também constatado por Silva et al. (2013) em mudas de maracujazeiro amarelo.

O maior comprimento de raiz, $32,5 \mathrm{~cm}$, foi encontrado em mudas provenientes do substrato com ausência de cinzas e adição de 4,39\% de gesso ao substrato comercial. Já na presença de cinzas, a melhor dose de gesso para este parâmetro foi de $2,48 \%$, o que proporcionou sistema radicular com 29,5 cm de comprimento (Figura 1C).

$\mathrm{Na}$ ausência de cinzas no substrato, o melhor resultado de massa de matéria seca de raízes foi estimado em 3,8 g planta-1, com uma proporção de $4,33 \%$ de gesso. Ao misturar cinzas ao substrato, em todas as dosagens de gesso obteve-se menor desenvolvimento do sistema radicular das mudas de baruzeiro. Sendo que a dose de $3,17 \%$ de gesso proporcionou o maior valor de massa seca de raízes, de 2,6 g planta-1 (Figura 1D).

Com respeito à massa seca da parte aérea, o efeito foi linear crescente para as doses de gesso adicionadas ao substrato na ausência de cinzas (Figura 1E). Resultado contrário, ou seja, linear decrescente se obteve com a presença de cinzas.

Quanto à massa seca total, observou resultado linear crescente as doses de gesso ao substrato. No entanto a adição de cinza implicou em efeito quadrático e com massa inferior, sendo que a dose de $2,70 \%$ de gesso ao substrato proporcionou a maior MSTO, 3,9 g planta-1 (Figura 1F).

Estes fatos se explicam provavelmente, devido quando da utilização do gesso nas suas maiores proporções, combinado com a cinza, aumentaram significativamente a quantidade de $\mathrm{Ca}++$ no substrato, o que pode ter inibido a absorção de $\mathrm{K}+\mathrm{e} \mathrm{Fe} 2+$ o que prejudicou o desenvolvimento das mudas, o que também foi constatado por Silva et al. (2013) em mudas de maracujazeiro amarelo.

Quando avaliou-se a qualidade das mudas através do IQD, a resposta foi linear crescente as dosagens de gesso adicionadas ao substrato (Figura 1G). Quando adicionou-se as cinzas ao substrato as mudas apresentaram índices inferiores, independentemente da dosagem, e a equação quadrática foi a que melhor se ajustou aos dados. Derivando a equação, a proporção de 3,03\% de gesso proporcionou um índice de 1,5. 
Figura 1. Diâmetro de caule (DC), número de folíolos por folha (NFF), comprimento de raiz (CR), massa seca de raiz (MSR), massa seca da parte aérea (MSPA), massa seca total (MST), índice de qualidade Dickson (IQD)de mudas de baruzeiro, em função de proporções de gesso e ausência e presença de adubação potássica no substrato. Orizona (GO), 2010.

(A)

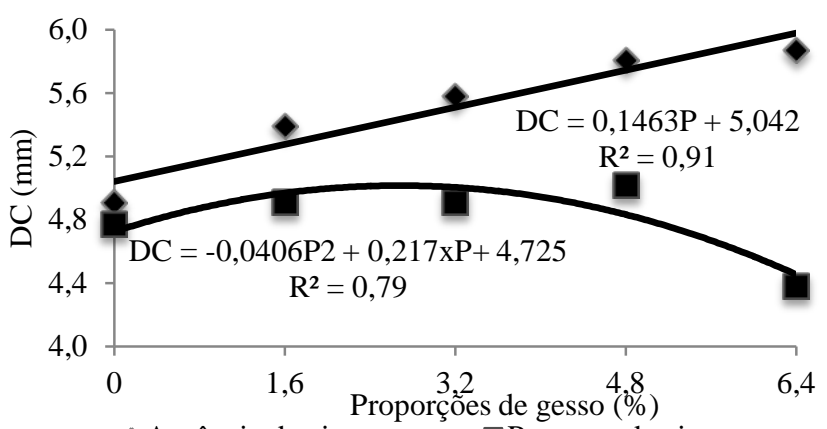

- Ausência de cinzas $\quad$ Presença de cinzas

(C)

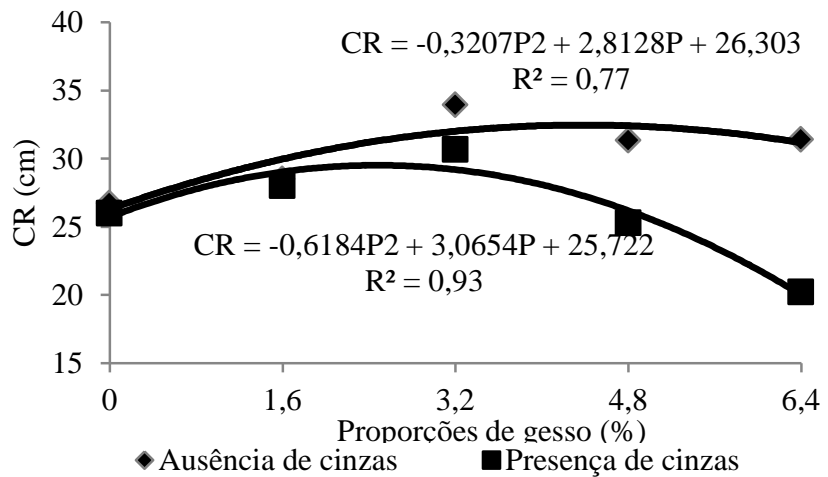

(E)

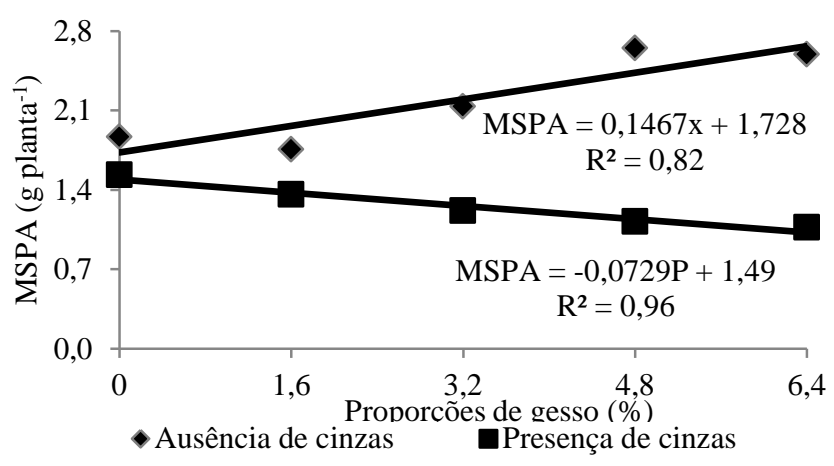

(B)

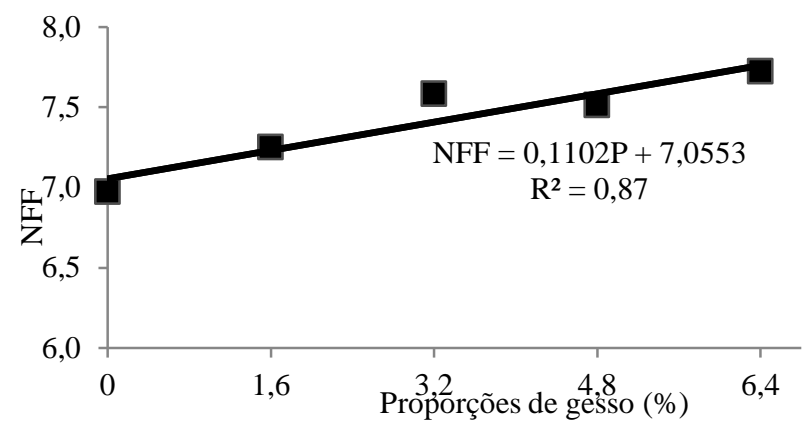

(D)

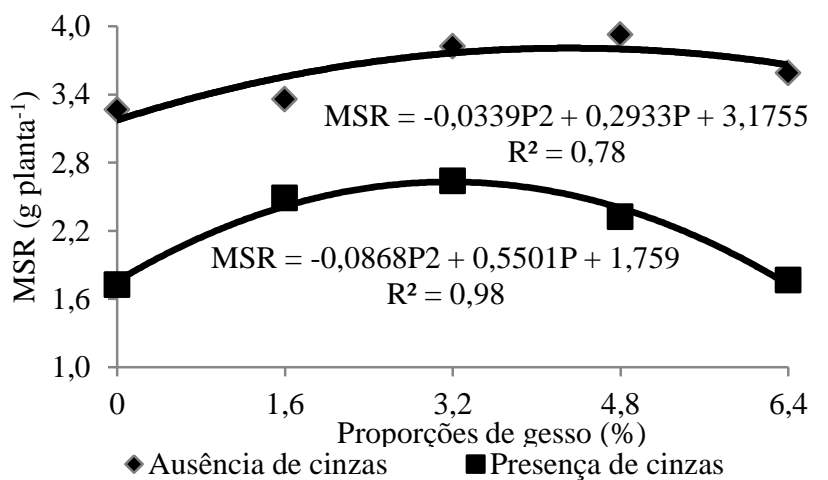

(F)

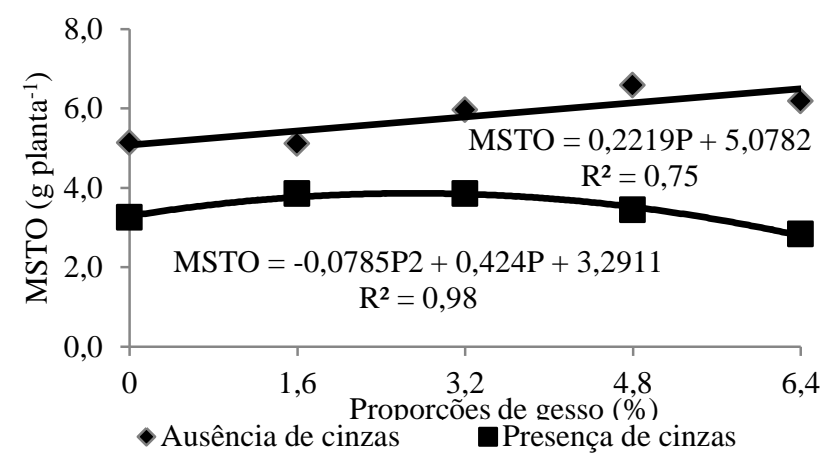

(G)

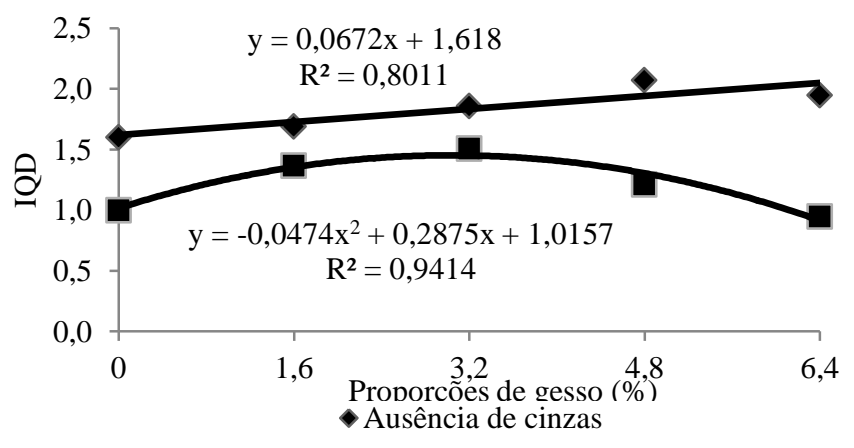

O gesso proporcionou maior sistema radicular das mudas de baruzeiro, o que explica o maior desenvolvimento da parte aérea, devido maior absorção de nutrientes do substrato, produzindo plantas de maior qualidade. Resultados estes, que corroboram com Silva et al. (2013), Garlet et al. (2013) e Ramos et al. (2010) e são contrários aos de Venturin 
et al. (1995), ao adicionarem gesso ao substrato para a produção de mudas de maracujá (Passiflora edulis Sims f. flavicarpa Deg), eucalipto (Eucaliptus badjensis), café (Coffea arabica L.) e de seringueira (Hevea sp.), respectivamente.

Porém, o gesso agrícola quando associado à cinza de madeira, resultou em mudas de baruzeiro com parâmetros de densenvolvimento inferiores, exceto com relação ao comprimento de raiz $(0 \%, 1,6 \%$ e $3,2 \%)$ e massa seca da parte aérea $(0 \%$ e $1,6 \%)$. A adição de gesso ao substrato produz mudas com melhor robustez e distribuição da biomassa, acarretando, de acordo com Caldeira et al. (2012), em um melhor equilíbrio da planta, porém sua associação com as cinzas prejudica a qualidade das mudas de baruzeiro. Efeito este provocado, provavelmente, pelo aumento no teor de $\mathrm{Ca} 2+$ e saturação por base da solução do substrato, pois esses dois insumos são fontes deste nutriente, e consequentemente inibição na absorção de $\mathrm{K}+$ e $\mathrm{Fe} 2+$, fato também constatado por Andreotti et al. (2000) e Silva et al. (2013), na cultura do milho e em mudas de maracujá, respectivamente

\section{CONCLUSÕES}

A adição de gesso agrícola ao substrato proporcionou melhor desenvolvimento inicial, além de produzir mudas de baruzeiro que apresentam resposta linear crescente com relação à qualidade. Enquanto, a adição de cinzas de madeira ao substrato comercial juntamente com o gesso, não favoreceu o desenvolvimento das mudas de baruzeiro, exceto com relação ao comprimento de raiz e massa seca da parte aérea, nas respectivas doses $0 \%, 1,6 \%$ e $3,2 \%$ e $0 \%$ e $1,6 \%$. Sendo, então, necessário realizar uma complementação do substrato comercial com nutrientes, para produzir mudas de baruzeiro com maior qualidade.

\section{REFERÊNCIAS BIBLIOGRÁFICAS}

ANDRADE, A. P.; BRITTO, C. C.; SILVA JÚNIOR, J.; COCOZZA, F. D. M.; SILVA, M. A. V. Estabelecimento inicial de plântulas de Myracrodruon urundeuva Allemão em diferentes substrato. Revista Árvore, Viçosa-MG, v.37, n.4, p.737-745, 2013.

ANDREOTTI, M.; SOUZA, E. C. A. DE; CRUSCIOL, C. A. C.; RODRIGUES, J. D.; BULL, L. T. Produção de Matéria seca e absorção de nutrientes pelo milho em razão as saturação por bases e da adubação potássica. Pesquisa Agropecuária Brasileira, Brasília, v. 35, n.12, 2437-2446, dezembro de 2000.

BROETTO, D.; BOTELHO, R. V.; MULlER, M. M. L.; KAWAKAMI, J.; TREMEA, A. Substratos para produção orgânica de mudas de maracujazeiro azedo. Revista Brasileira de Agroecologia, Guarapuava, v.4, n.2, p.1987-1990, 2009.

CALDEIRA, M. V. W.; DELARMELINA, W. M.; LÜGE, S. G.; GOMES, D. R.; GONÇALVES, E. O.; ALVES, A. F. Biossólido na composição de substrato para a produção de mudas de Tectona grandis. Floresta, Curitiba, PR, v. 42, n. 1, p. 77 - 84. 2012.
CARRAZZA, L.; ÁVILLA, J. C. Aproveitamento integral do fruto baru (Dipteryx alata). 2. ed. Brasília: Instituto Sociedade, População e Natureza (ISPN), 2010. 56 p.

CORREA, A. F.; LUZ, P. B.; SERAFIM, M. E.; FAVARE, H. G. Efeito da estrutura do solo e de doses de cinza na densidade do substrato para produção de mudas de maracujazeiro In: Congresso de Iniciação Científica, $5^{\text {a }}$. (JC), 2013, Cáceres/MT. Anais... Cáceres/MT: PróReitoria de Pesquisa e Pós-Graduação - PRPPG, 2013. Vol. 8 (2013). Cód. 9100. ISSN ONLINE 2237-9258. CDROM 2178-7492.

DICKSON, A.; LEAF, A. L.; HOSNER, J. F. Quality appraisal of white spruce and white pine seedling stock in nurseries. For. Chron., v. 36, p. 10-13, 1960.

FERREIRA, D.F. Sisvar: A computer statistical analysis system. Ciência e Agrotecnologia, Lavras, v.35, n.6, p.1039-1042, nov.-dez. 2011.

FERREIRA, R. B.; OLIVEIRA JÚNIOR, J. P.; NAVES, R. V.; SALGADO, A. L. Desenvolvimento de mudas de Annona crassiflora Mart. (Araticum) em substratos com cinzas de cana. Pesquisa Agropecuária Tropical, Goiânia - GO, v. 39, n. 1, p. 18-24, 2009.

FREIRE, F. M.; COELHO, A. M.; BARROS, N. F.; BARROS FILHO, N. F.; NEVES, J. C. L. Manejo da fertilidade do solo no Sistema de Integração LavouraPecuária-Floresta. In. Integração Lavoura-PecuáriaFloresta (informe Agropecuário), Belo Horizonte, v. 31, n. 257, p. 25-36, 2010.

GARLET, J.; DELAREZI, P.; SOUZA, G. F. Produção de mudas de Eucaliptus badjensis em diferentes composições de substrato. Anais. In: II Congresso Brasileiro de Eucalipto, São Paulo, 2013.

OLIVEIRA, J. S.; NUNES, H. B.; SOUZA, A, X. Avaliação da taxa de germinação e do desenvolvimento de Barriguda (Cavanillesia arbórea) com uso de substratos alternativos. Revista de Biologia e Ciências da Terra, Universidade Estadual da Paraíba, v. 11, n. 1, p. 83-88, 2011.

PRADO, R. DE M.; CORRÊA, M. C. DE M.; PEREIRA, L.; CINTRA, A. C. DE O.; NATALE, W. Cinza da indústria de cerâmica na produção de mudas de goiabeira: efeito no crescimento e na produção de matéria seca. Revista de Agricultura, Piracicaba, v.78, n.1, p.25-35, 2003.

RAMOS, L.; NANNETTI, D. C.; CARMO, D. L. Efeito da adição do gesso agrícola em substrato no desenvolvimento de mudas de cafeeiro. Revista Agrogeoambiental. Inconfidentes, v.2, n.3, p.97-103, 2010 .

SANTOS, R. A.; MONÇÃO, O. P.; SILVA, B. S. O.; SANTOS, J. J. X.; BARROS, B. C.; SOUZA, A. X. Influência de substratos e bandejas para a produção de 
mudas de tomateiro rasteiro. Cultivando o Saber, Cascavel, v.6, n.1, p.95-102, 2013.

SILVA, C. J.; SILVA, C. A.; GOLINSKI, J.; FREITAS, C. A,; CASTRO, Y,. O. Adição de gesso agrícola e cinza de madeira ao substrato no desenvolvimento de mudas de maracujazeiro (Passiflora edulis Sims f. flavicarpa Deg.). Revista Verde de Agroecologia e Desenvolvimento Sustentável, Mossoró, RN, v. 8, n. 2, p. 72-76, 2013.

SILVA, P. S.; SOUZA, R. B.; JASSE, M. E. C.; GUEDES, I. M. R.; GOBBI, S. J.; REZENDE, F. V.; LUZ, M. Produção de mudas orgânicas de alface americana em substratos a base de fibra de coco verde. Anais. In: Congresso Brasileiro de Horticultura, 49, 2009, Águas de Lindoia, v.27, n.2 (Suplemento - CD Rom), 2009.
SOUZA, D. M. G.; LOBATO, E. Cerrado: correção do solo e adubação. 2. ed., Brasília, DF: Embrapa Informação Tecnológica, 2004. 416p.

TRAZZI, P. A.; CALDEIRA, M. V. W.; PASSOS, R. R.; GONÇALVES, E. O. Substratos de origem orgânica para produção de mudas de teca (Tectona grandis Linn. F.). Ciência Florestal, Santa Maria, v. 23, n. 3, p. 401409, 2013.

VENTURIN, N.; NOGUEIRA, F. D.; COQUEIRO, G. R. Efeito do fosfato de Araxá, calcário e gesso em mudas de seringueira (Hevea sp.). Pesquisa Agropecuária Brasileira, Brasília, v.30, n.2, p.187-193, 1995. 